\title{
Inhibition of Replication Induces Non-Apoptotic Cell Death in Fibroblast Cell Lines Derived from LEC Rats
}

\author{
Masanobu HAYASHI ${ }^{1)}$, Taku HAMASU ${ }^{1)}$, Daiji ENDOH ${ }^{1)}$, Reiko SHIMOJIMA ${ }^{1)}$ and Toyo OKUI ${ }^{2)}$ \\ ${ }^{1)}$ Department of Veterinary Radiology, School of Veterinary Medicine, Rakuno Gakuen University, Ebetsu 069-8501 and ${ }^{2)}$ Hokkaido \\ Institute of Public Health, Sapporo 060-0819, Japan
}

(Received 29 July 2002/Accepted 13 November 2002)

ABSTRACT. Hydroxyurea (HU), an anticancer drug, inhibits ribonucleoside diphosphate reductase and reduces pool sizes of deoxyribonucleoside triphosphate (dNTP). The reduction of dNTP results in inhibition of DNA replication. The cytotoxic effect of HU was investigated using fibroblast cell lines from LEC rats. LEC rat cells showed significantly higher sensitivity to HU than did cell lines from control WKAH rats. No significant differences were observed between the percentages of apoptotic cells in either LEC or WKAH rat cells that had been treated with HU and those that had not been treated with HU. LEC rat cells also showed significantly higher sensitivity to aphidicolin, which blocks DNA synthesis by inhibiting DNA polymerase $\alpha$, than did WKAH rat cells. In both LEC and WKAH rat cells, intensified bands of p53 protein were observed immediately after treatment with HU. Although the high level of p53 protein persisted in WKAH rat cells until $6 \mathrm{hr}$ post-incubation time after treatment with HU, the level of p53 protein had decreased at $6 \mathrm{hr}$ postincubation time in LEC rat cells. When the cells were X-irradiated in the absence or presence of $\mathrm{HU}$, the ratio of the surviving fraction without $\mathrm{HU}$ to that with $\mathrm{HU}$ only slightly increased after X-irradiation in WKAH rat cells. In contrast, the ratio in LEC rat cells significantly increased after X-irradiation in a dose-dependent manner.

KEY WORDS: cytotoxicity, hydroxyurea, LEC rat cell, p53, radiosensitizing effect.

J. Vet. Med. Sci. 65(2): 249-254, 2003

A variety of chemotherapeutic agents are widely used in clinical practice to treat many types of human and animal malignancies. Growing evidence now suggests that the efficacy of many anticancer drugs is related to the propensity of target tumor cells to respond to these drugs by undergoing apoptosis $[4,5,15]$. Hydroxyurea (HU) acts to inhibit ribonucleoside diphosphate reductase and to reduce the pool sizes of deoxyribonucleoside triphosphate (dNTP) in cells $[30,31]$. The reduction in the pool sizes of dNTP inhibits DNA replication in tumor cells. It has been reported that treatment of chronic myelogenous leukemia lymphocytes [2] and human erythroleukemia cells [10] with HU induces apoptosis. Gottifredi et al. [8] showed that p53 protein accumulates after treatment of human colorectal carcinoma cells with HU. It is well known that p53 protein regulates induction of apoptosis via the cell cycle checkpoint pathway [33]. Indeed, it has been shown that normal p53 function is required for rapid and efficient induction of apoptosis in human lymphoblastoid cells by treatment with HU [9]. However, Alaoui et al. [1] showed that HU does not induce apoptosis in a hamster fibrosarcoma cell line. Furthermore, HU-induced cell cycle arrest is highly reversible and cellular morphologies remain relatively normal, in contrast to the p53-dependent response to DNA damage, characterized by long-term arrest of the cell cycle and irregular cellular morphologies [3]. HU can cause a reversible late G1/early Sphase arrest independent of p53 [3]. HU also induces a p53dependent G0 or early G1-phase arrest in the absence of replicative DNA synthesis or detectable DNA damage in normal human fibroblasts [21]. Thus, the role of apoptosis and p53 protein in the cytotoxicity of HU remains unclear.

It has been reported that $\mathrm{HU}$ enhances the radiosensitivity of tumor cells in vitro and in vivo [26, 29, 32]. The radiosensitizing effect of $\mathrm{HU}$ is thought to be due to a primary cytotoxic effect of HU on the mid to late S-phase population, which may be a radioresistant population $[17,29]$. Alternatively, when $\mathrm{HU}$ is administered in combination with ionizing radiation, HU inhibits DNA synthesis in the repair process of DNA damage induced by ionizing radiation, resulting in cell death $[6,7]$. It has been reported that the level of p53 protein transiently increases following exposure of normal cells to ionizing radiation and that $\mathrm{p} 53$ protein plays a critical role in radiation-induced G1-phase arrest $[16,23]$. However, the role of $\mathrm{p} 53$ protein in the radiosensitizing effect of HU remains unclear.

The LEC rat strain was established at the Center for Experimental Plants and Animals, Hokkaido University [28]. Rats of this strain suffer from spontaneous fulminant hepatitis associated with severe jaundice at about 4 months of age. Other characteristics of LEC rats are a high incidence of spontaneous liver cancer in long-surviving individuals [34] and an increased sensitivity in vivo and in vitro to ionizing radiation [12]. In our previous studies, we found that fibroblast cell lines from LEC rats were more sensitive to X-irradiation than were cells from a control strain of WKAH rats [11]. In the case of WKAH rat cells, the level of $\mathrm{p} 53$ protein increases from 1 to $6 \mathrm{hr}$ post-incubation time after X-irradiation. On the other hand, the radiation-induced transient increase in the level of p53 protein is not observed in LEC rat cells [14]. In the course of analysis of the mechanisms of high sensitivity of LEC rat cells to X-irradiation, we found that LEC rat cells are more sensitive to blocking agents of DNA synthesis than are WKAH rat cells. In the present study, we examined the cytotoxic and radiosensitiz- 
ing effects of HU and the level of p53 protein after treatment with HU in LEC rat cells.

\section{MATERIALS AND METHODS}

Culture of cells and drug treatments: Rat fibroblast cell lines were established from lungs of LEC and WKAH rats by SV 40 immortalization as described previously [11]. The cells were grown in a monolayer culture in Eagle's minimum essential medium (MEM) containing 10\% fetal calf serum. The cell cultures were kept at ambient humidity and $37^{\circ} \mathrm{C}$ in an atmosphere containing $5 \% \mathrm{CO}_{2}$.

After the medium had been removed from the plates, the cells were washed with phosphate-buffered saline (PBS), pH 7.2, and treated with HU (Sigma Aldrich Chemical Co.) for $3 \mathrm{hr}$ or with aphidicolin (Wako Chemical Co.) for $24 \mathrm{hr}$ at various concentrations. After the medium containing the drug had been removed, the cells were washed with PBS. Fresh MEM was added to the plate and the plates were returned to the incubator.

$X$-irradiation and $U V$-irradiation: After treatment of the cells with $\mathrm{HU}$ for $1 \mathrm{hr}$, the cells were X-irradiated using a Hitachi MBR-1520R X-ray generator operated at $150 \mathrm{kV}$ and $15 \mathrm{~mA}$ with a $0.5 \mathrm{~mm} \mathrm{Cu}+1.0 \mathrm{~mm} \mathrm{Al} \mathrm{filter} \mathrm{at} \mathrm{a} \mathrm{dose}$ rate of $0.95 \mathrm{~Gy} / \mathrm{min}$. X-irradiated cells were incubated for 2 $\mathrm{hr}$ in the presence of HU and incubated in fresh MEM without HU.

Since we have reported a higher sensitivity of LEC rat cells in induction of apoptosis than that of WKAH rat cells to UV-irradiation [13], UV-irradiation was used as an apoptosis-inducing treatment in the present study. After the medium was removed from the plates, the cells were washed with PBS and UV-irradiated at a flux rate of $1.0 \mathrm{~J} / \mathrm{m}^{2} / \mathrm{sec}$ by using a Toshiba germicidal mercury vapor lamp. Immediately after UV-irradiation, a fresh medium was added and the plates were returned to the incubator.

Colony-forming assay: Cell survival was determined using the conventional colony-forming assay. Propagated cells were collected by trypsinization, and $2-50 \times 10^{2}$ viable cells were plated into 6-cm dishes. After the cells had been treated with drugs or exposed to X-rays, the cells were incubated for 2 weeks. The plates were methanol-fixed and stained with May-Grunwald and Giemsa, and then colonies containing more than 50 cells were counted as survivors under a dissecting microscope.

Flow cytometry: The apoptotic cells were labeled with fluorescein-dUTP by using a Mebstain apoptosis kit direct (Medical \& Biological Laboratories Co.) according to the manufacturer's instructions. Briefly, after treatment with HU or exposure to UV, the cells $\left(1 \times 10^{6}\right)$ were incubated in growth medium at $37^{\circ} \mathrm{C}$ for $0-72 \mathrm{hr}$ and collected. The cells were washed several times with PBS containing $0.2 \% \mathrm{BSA}$. The cells were fixed with $0.1 \mathrm{M} \mathrm{NaH}_{2} \mathrm{PO}_{4}$ containing $4 \%$ paraformaldehyde at $4{ }^{\circ} \mathrm{C}$ for $30 \mathrm{~min}$, washed 2 times with PBS containing $0.2 \%$ BSA, and then pelleted by centrifugation at $500 \times \mathrm{g}$. The cells were fixed in $5 \mathrm{ml}$ of cold $70 \%$ ethanol for $30 \mathrm{~min}$ at room temperature and stored at $-20^{\circ} \mathrm{C}$.
Just prior to flow cytometric analysis, individual samples were labeled with fluorescein-dUTP. Fluorescence was measured with a Coulter EPICS EL flow cytometer using a 530 -nm filter. The percentage of apoptotic cells was determined using multicycle software.

Immunoblotting: After treatment of the cells $\left(1 \times 10^{6}\right.$ to 5 $\times 10^{6}$ ) with $\mathrm{HU}$, the cells were incubated at $37^{\circ} \mathrm{C}$ for $0-6 \mathrm{hr}$, harvested by trypsinization, washed with $\mathrm{PBS}$, and then pelleted by centrifugation at $500 \times \mathrm{g}$. The cells were counted and solubilized in Laemmli sample buffer as described by Kastan et al. [16, 22]. A modified Lowry assay was used to quantitate relative protein levels in the samples, and extracts were loaded so that equivalent cell numbers and/or equivalent protein amounts were loaded in each comparable set of lanes. After sodium dodecyl sulfate-polyacrylamide gel electrophoresis and wet electrotransfer (Mini TransBlot Cell, BioRad) to polyvinylidene fluoride (PVDF) paper (Immobilon-P, Millipore), equivalent protein loading was confirmed by staining the PVDF paper with amido black. A monoclonal antibody to p53 (Pab240) was obtained from Oncogene Science, Inc. Peroxidase-labeled anti-mouse immunoglobulin antibody was obtained from Zymed Laboratories, Inc. The proteins were detected with ECL-Western blot reagents (Amersham Co.) according to the protocols provided by the manufacturers.

\section{RESULTS}

When the cytotoxic effect of HU on cell survival was examined using a colony-forming assay, the surviving fractions decreased in both fibroblast cell lines from LEC and WKAH rats in a dose-dependent manner, and LEC rat cells showed significantly higher sensitivity to HU than did WKAH rat cells (Fig. 1). The doses of HU required to reduce cell survival to $50 \%\left(\mathrm{ED}_{50}\right)$ were approximately 1 $\mathrm{mM}$ for LEC rat cells and $10 \mathrm{mM}$ for WKAH rat cells. To determine whether the high sensitivity of LEC rat cells to $\mathrm{HU}$ is due to induction of apoptosis by $\mathrm{HU}$, the apoptotic cells were analyzed using a flow cytometer after treatment with HU. No significant level of apoptotic cells was observed in either LEC and WKAH rat cell populations from 0 to $48 \mathrm{hr}$ post-incubation time after treatment with 5 $\mathrm{mM}$ of HU (Fig. 2). The percentages of apoptotic cells slightly increased at $72 \mathrm{hr}$ post-incubation time after treatment with $\mathrm{HU}$, but no significant differences were observed between the percentages of apoptotic cells in either LEC or WKAH rat cells that had been treated with HU and those that had not been treated with HU (Fig. 2). Since we have showed a higher sensitivity of LEC rat cells in induction of apoptosis than that of WKAH rat cells to UV-irradiation [13], UV-irradiation was used as an apoptosis-inducing treatment in the present study. The proportion of apoptotic cells in the total LEC rat cell population was approximately $18 \%$ at $24 \mathrm{hr}$ post-incubation time after UV-irradiation at 10 $\mathrm{J} / \mathrm{m}^{2}$.

HU inhibits ribonucleoside diphosphate reductase, reducing the pool sizes of dNTP in the cells, and the reduction in 


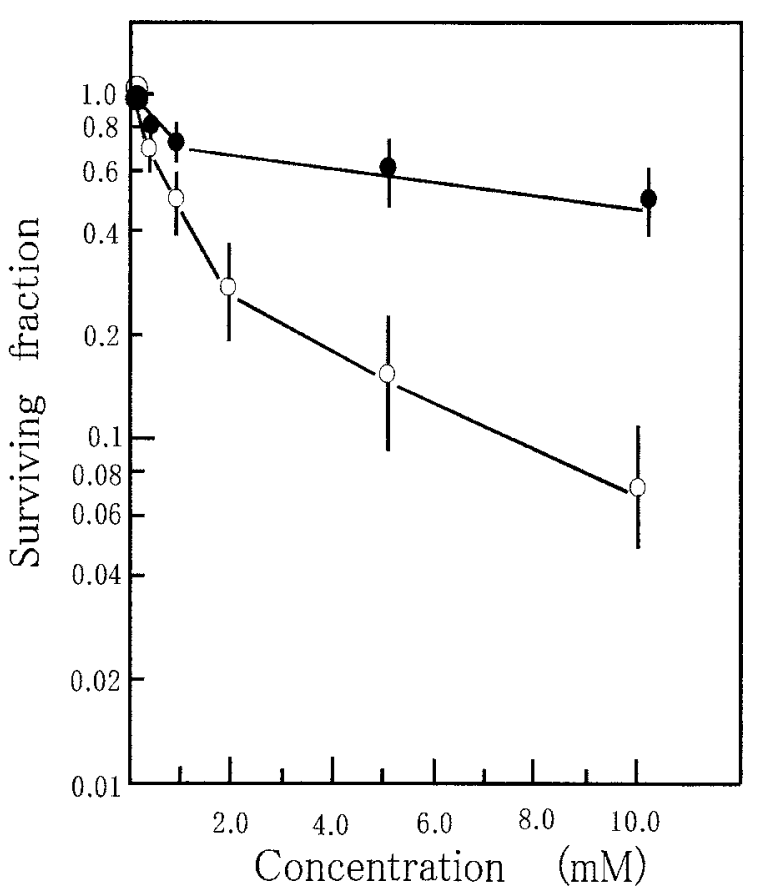

Fig. 1. Cytotoxic effect of HU on the survival of fibroblast cell lines from LEC and WKAH rats. The fibroblast cell lines from LEC $(\bigcirc)$ and WKAH $(\bigcirc)$ rats were treated with $\mathrm{HU}$ at $37^{\circ} \mathrm{C}$ for $3 \mathrm{hr}$. Each value represents the average from four separate experiments. Error bars represent the standard deviations of mean values.

the pool sizes of dNTP results in blockage of DNA synthesis. To determine whether the strong cytotoxic effect of $\mathrm{HU}$ on LEC rat cells is due to the reduction in pool sizes of dNTP or to the inhibition of DNA synthesis, LEC and WKAH rat cells were treated with aphidicolin, which blocks DNA synthesis by inhibiting DNA polymerase $\alpha$. Aphidicolin does not reduce the pool sizes of dNTP in the cells. The surviving fractions decreased in both fibroblast cell lines from LEC and WKAH rats after treatment with aphidicolin, and LEC rat cells showed significantly higher sensitivity to aphidicolin than did WKAH rat cells (Fig. 3). ED ED $_{50}$ was $0.03 \mu \mathrm{M}$ for LEC rat cells and $0.36 \mu \mathrm{M}$ for WKAH rat cells.

It has been shown that $\mathrm{p} 53$ protein accumulates when DNA synthesis is blocked [8]. It is well known that $\mathrm{p} 53$ protein arrests the progress of the cell cycle at G1/S-phase [16, 23]. To determine whether the high sensitivity of LEC rat cells to HU is associated with the accumulation of $\mathrm{p} 53$ protein induced by HU, amounts of p53 protein in LEC and WKAH rat cells were analyzed by immunoblotting after treatment with HU (Fig. 4). In both LEC and WKAH rat cells, intensified bands of p53 protein were observed immediately after treatment with $5 \mathrm{mM}$ of $\mathrm{HU}$ for $3 \mathrm{hr}$, compared with the bands of p53 protein from untreated cells. In WKAH rat cells, the high level of $\mathrm{p} 53$ protein persisted until $6 \mathrm{hr}$ post-incubation time after treatment with HU. The

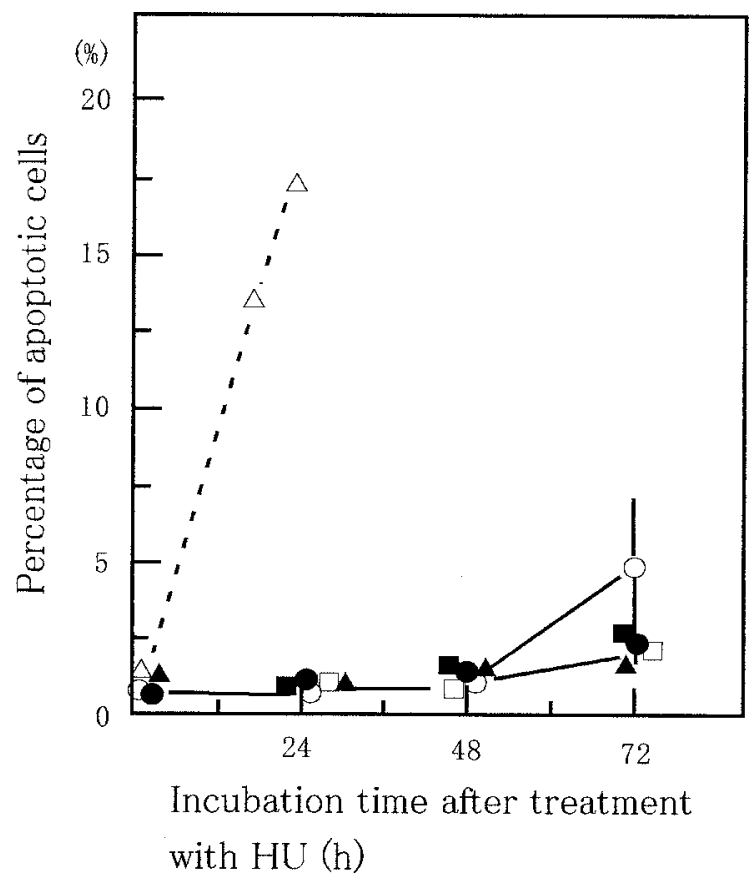

Fig. 2. Induction of apoptosis in LEC and WKAH rat cells after treatment with HU and exposure to UV. After treatment of $\operatorname{LEC}(\bigcirc, \square)$ and $\operatorname{WKAH}(\boldsymbol{Q}, \mathbf{\square})$ rat cells with $\mathrm{HU}$ at $5 \mathrm{mM}$ $(\square, \square)$ or without $\mathrm{HU}(\bigcirc, \mathcal{O})$, and exposure of LEC $(\triangle)$ and WKAH ( $\Delta$ ) rat cells to UV-rays at $10 \mathrm{~J} / \mathrm{m}^{2}$, the cells were incubated at $37^{\circ} \mathrm{C}$ for $0-72 \mathrm{hr}$, and the number of apoptotic cells was counted using a flow cytometer at each incubation time. Each value represents the average from four separate experiments. The standard deviations were within symbols at some points.

level of p53 protein had decreased to that of untreated cells at $24 \mathrm{hr}$ post-incubation time. In contrast, the level of p53 protein had significantly decreased in LEC rat cells at $6 \mathrm{hr}$ post-incubation time compared with the level immediately after treatment with HU.

To investigate the radiosenisitizing effects of $\mathrm{HU}$ on the cell lines from LEC and WKAH rats, the cells were X-irradiated in the absence or presence of $5 \mathrm{mM} \mathrm{HU}$. In the unirradiated WKAH cells, the enhancement ratio, i.e., the ratio of the surviving fraction without HU to that with HU, was 1.67. The ratio only slightly increased after X-irradiation of WKAH rat cells (1.73-2.02, Fig. 5). In the case of LEC rat cells, the ratio was 6.67 for unirradiated cells and significantly increased after X-irradiation in a dose-dependent manner (7.9, 10.0 and 56.8 for 2, 4 and 6 Gy, respectively).

\section{DISUCUSSION}

It has been suggested that the efficacy of many anticancer drugs is related to the propensity of target tumor cells to respond to these drugs by undergoing apoptosis [4, 5, 15]. Although it has been reported that the treatment of chronic myelogenous leukemia lymphocytes [2] and human erythro- 


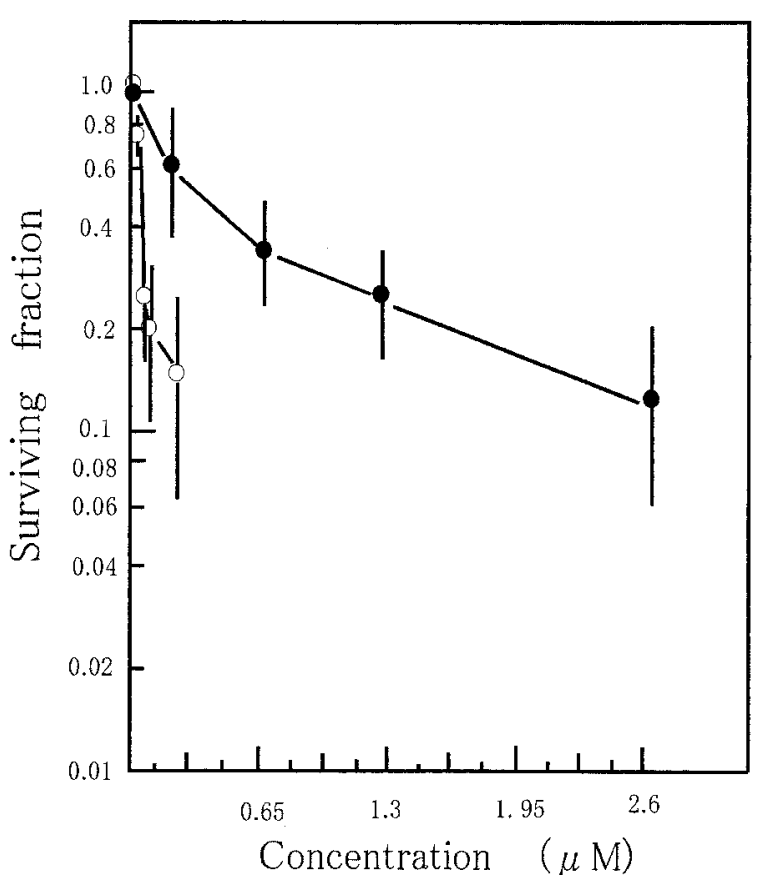

Fig. 3. Cytotoxic effect of aphidicolin on the survival of LEC and WKAH rat cells. LEC $(\bigcirc)$ and WKAH $(\bigcirc)$ rat cells were treated with aphidicolin at $37^{\circ} \mathrm{C}$ for $24 \mathrm{hr}$. Error bars represent the standard deviations of mean values $(n=4)$.

leukemia cells [10] with HU induces apoptosis, HU did not induce apoptosis in a hamster fibrosarcoma cell line [2]. Furthermore, it has been reported that HU-induced cell cycle arrest is highly reversible and that cellular morphologies remain relatively normal [3]. Thus, the role of apoptosis in the anticancer activity of $\mathrm{HU}$ is not clear. In the present study, we found that LEC rat fibroblast cell lines showed significantly higher sensitivity to HU than did WKAH rat cells (Fig. 1). LEC rat cells were approximately ten times more sensitive to HU than were WKAH rat cells in terms of $\mathrm{ED}_{50}$. However, no significant differences were observed between the percentages of apoptotic cells in either LEC or WKAH rat cells that had been treated with HU and those that had not been treated with HU (Fig. 2). These results suggest that the strong cytotoxic effect of $\mathrm{HU}$ on LEC rat cells is not due to induction of apoptosis in LEC rat cells. Induction of apoptosis by HU may occur in only some types of cells such as cells of haemopoietic lineage. It is well known that survival curve obtained by colony-forming assay shows a reproductive cell death following a variety treatment of cells with physical and chemical agents such as exposure to ionizing radiation. The reason why LEC rat cells show a high sensitivity in reproductive cell death to treatment with $\mathrm{HU}$ remains unclear yet. A study to determine whether an induction of necrosis is associated with cytotoxic effect of HU in LEC rat cells is now in progress.

Aphidicolin inhibits cellular DNA synthesis by mecha-

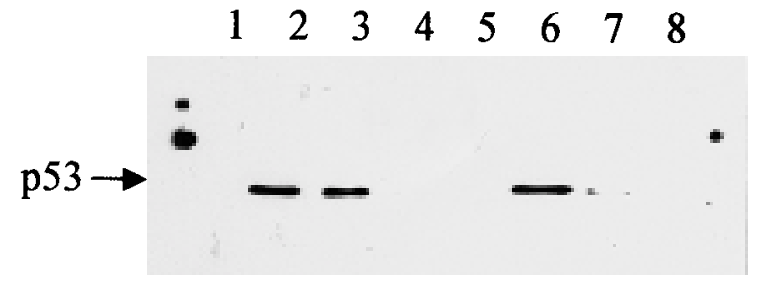

Fig. 4. Expression of the p53 protein in LEC and WKAH rat cells after treatment with HU. After WKAH rat cells (lanes 2-4) and LEC rat cells (lanes 6-8) had been treated with HU at $5 \mathrm{mM}$ for $3 \mathrm{hr}$, the cells were incubated at $37^{\circ} \mathrm{C}$ for 0 (lanes 2 and 6), 6 (lanes 3 and 7) and 24 (lanes 4 and 8) hr. Lanes 1 and 5 represent untreated WKAH and LEC rat cells, respectively.

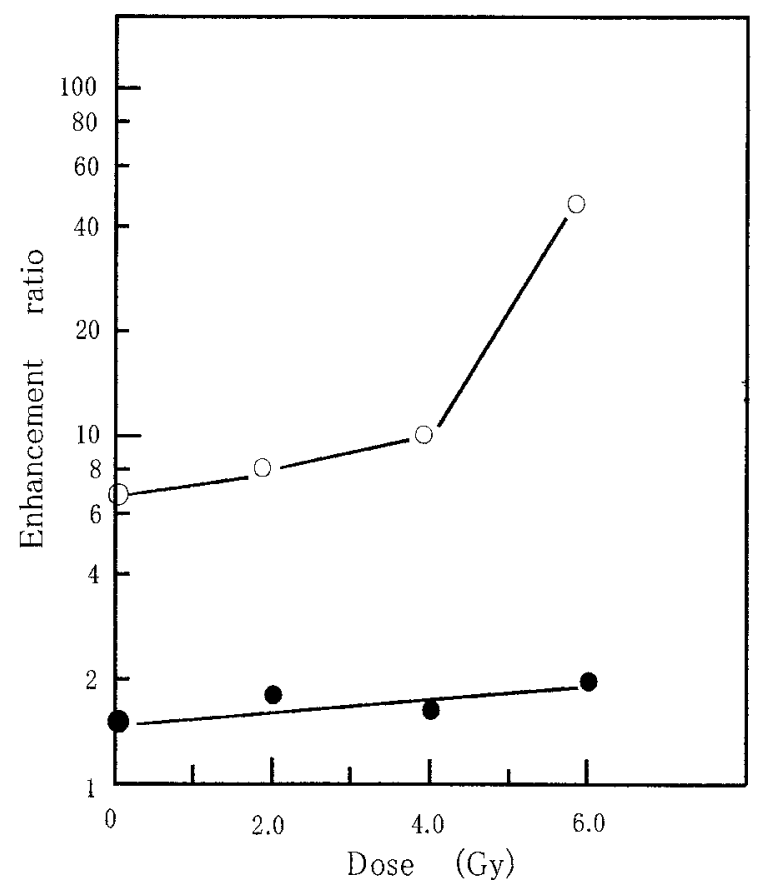

Fig. 5. Radiosensitizing effect of HU in LEC and WKAH rat cells. After treatment of LEC $(\bigcirc)$ and WKAH $(\mathbf{O})$ rat cells with $\mathrm{HU}$ at $5 \mathrm{mM}$ for $1 \mathrm{hr}$, the cells were $\mathrm{X}$-irradiated, and the $\mathrm{X}$-irradiated cells were incubated for $2 \mathrm{hr}$ in the presence of 5 $\mathrm{mM}$ HU. Enhancement ratio is the surviving fraction of the unirradiated or X-irradiated cells in the absence of HU/the surviving fraction of the unirradiated or $\mathrm{X}$-irradiated cells in the presence of $\mathrm{HU}$ at $5 \mathrm{mM}$. Each value represents the average from four separate experiments.

nisms different from those of HU. HU inhibits ribonucleoside diphosphate reductase and reduces pool sizes of dNTP in cells, and the reduction in the pool sizes of dNTP results in blockage of DNA synthesis [30]. Aphidicolin blocks DNA synthesis by inhibiting DNA polymerase $\alpha$ and does not reduce the pool sizes of dNTP in cells. LEC rat cells showed significantly higher sensitivity to aphidicolin than 
did WKAH rat cells (Fig. 3). LEC rat cells were also approximately ten times more sensitive to aphidicolin than were WKAH rat cells in terms of $\mathrm{ED}_{50}$. These results suggest that the blockage of DNA synthesis may cause the strong cytotoxic effect of HU on LEC rat cells, although a possibility cannot be excluded that the reduction in the pool sizes of dNTP may affect the cytotoxic effect of HU.

Stress signals that can activate $\mathrm{p} 53$ are initiated by agents that generate DNA strand breaks, stalled DNA replication forks, ribonucleotide deprivation, hypoxia, and other forms of cellular trauma $[8,16,23,33]$. In general, the induction of p53 is manifested by increased levels and activity of the protein through posttranscriptional mechanisms. Through its function as a transcriptional activator and repressor, a number of genes that control the cell cycle, cell death and other cellular functions are downstream targets of p53. Gottifredi et al. [8] showed that p53 protein accumulates after treatment of human colorectal carcinoma cells with HU. Furthermore, it has been reported that induction of apoptosis by treatment with $\mathrm{HU}$ requires normal p53 functions in human B lymphoblastoid cell lines [9]. In the present study, levels of p53 protein increased immediately after treatment with HU in both LEC and WKAH rat cells, and no significant difference was observed between the levels of $\mathrm{p} 53$ protein in LEC and WKAH rat cells (Fig. 4). The induction of p53 protein by HU rapidly disappeared in LEC rat cells but did not in WKAH rat cells. The mechanisms of the rapid decrease in p53 protein and the effect of the rapid disappearance of p53 protein on cytotoxicity of HU in LEC rat cells are not clear. Since no significant differences were observed between the percentages of apoptotic cells in either LEC or WKAH rat cells that had been treated with HU and those that had not been treated with HU, the increase in the level of p53 protein immediately after treatment of the cells with HU may not result in the induction of apoptosis in the rat fibroblast cell lines. Furthermore, whether the level of $\mathrm{p} 53$ protein is maintained or not after treatment with HU may not be directly associated with induction of apoptosis. HU induces a p53-dependent G0- or early G1-phase arrest in the absence of replicative DNA synthesis or detectable DNA damage in normal human fibroblasts [21]. Furthermore, it has been reported that treatment of cells with HU leads to activation of cell cycle check point protein kinases such as chk2 [20,22]. A study to determine whether the activation of cell cycle check point protein kinases by HU plays a role in the cytotoxicity of $\mathrm{HU}$ in LEC rat cells is now in progress.

$\mathrm{HU}$ is used in combination with ionizing radiation in tumor therapy $[18,19,26]$, since it has been reported that $\mathrm{HU}$ increases radiosensitivity of the cells in vitro and in vivo $[26,29,32]$. In the present study, enhancement of cell death was observed in both HU-treated LEC and WKAH rat cells compared with that in untreated cells after X-irradiation (Fig. 5). However, the degree of enhancement of cell death by HU was significantly different between X-irradiated LEC and WKAH rat cells. Although the enhancement ratio was increased by $\mathrm{X}$-irradiation in a dose-dependent manner in LEC rat cells, the ratio in WKAH rat cells only slightly increased after X-irradiation. Thus, a combination of HU with ionizing radiation showed synergistic interaction in LEC rat cells, but only an additive effect was observed in WKAH rat cells. The mechanisms underlying the different interactions of $\mathrm{HU}$ and ionizing radiation in LEC and WKAH rat cells are not known. Cells in S-phase, which are a radioresistant population, are thought to have higher sensitive to $\mathrm{HU}$ than do cells in other phases of the cell cycle [17, 29]. In the case of WKAH rat cells, the radiosensitizing effect of HU may be primarily due to the cytotoxicity to the cells in S-phase. Therefore, only an additive effect may be observed after X-irradiation of the cells in the presence of HU. It has been reported that HU inhibits DNA synthesis in the repair process of DNA damage induced by ionizing radiation [6, 7, 32]. In this case, it may be expected that HU interacts synergistically with ionizing radiation. Therefore, radiosensitizing effect of HU may be mainly due to the inhibition of DNA repair in LEC rat cells. We have reported that LEC rat cells show a reduced level of repair of DNA double strand breaks $[11,25]$, which seems to be the type of DNA damage most responsible for radiation-induced cell death [27]. The reduced level of repair of DNA damage in LEC rat cells may affect the interaction of HU and ionizing radiation.

A variety of chemotherapeutic agents are widely used in clinical practice to treat many types of human and animal malignancies. Anticancer drugs are used in combination with ionizing radiation. However, the efficacy of each anticancer drug in killing tumor cells and the degrees of radiosensitizing effects of the drugs may be dependent on the type of cells. LEC rat cells showed high sensitivities to several chemotherapeutic agents, such as cis-platin (data not shown), bleomycin [24] and HU as well as to synergistic interaction of HU and ionizing radiation. Therefore, LEC rat cells provide a useful model for understanding the mechanisms underlying cytotoxicities of anticancer drugs and interactions of anticancer drugs and ionizing radiation.

ACKNOWLEDGEMENT. This work was supported in part by a grant-in-aid from the Ministry of Education, Science, Sports and Culture of Japan.

\section{REFERENCES}

1. Alaoui, S. El, Lawry, J. and Griffin, M. 1997. The cell cycle and induction of apoptosis in a hamster fibrosarcoma cell line treated with anti-cancer drugs: Its importance to solid tumor chemotherapy. J. Neurooncol. 31: 195-207.

2. Anand, S., Verma, H., Kumar, L. and Singh, H. 1995. Induction of apoptosis in chronic myelogenous leukemia lymphocytes by hydroxyurea and adriamycin. Cancer Lett. 88: 101105.

3. Atkin, C. L., Thlander, L., Reichard, P. and Lang, G. 1973. Iron and free radical in ribonucleotide reductase. J. Biol. Chem. 248: 7464-7472.

4. Dive, C. and Hickmann, J. A. 1991. Drug target interactions: only the first step in the commitment to a programmed cell 
death. Br. J. Cancer 64: 192-196.

5. Dyson, J. E. D., Simmons, D. M., Daniel, J., McLaughlin, J. M., Quirke, P. and Bird, C. C. 1986. Kinetics and physical studies of cell death induced by chemotherapeutic agents or hyperthermia. Cell Tissue Kinet. 19: 311-324.

6. Fram, R. J. and Kufe, D. W. 1985. Inhibition of DNA excision repair and the repair of X-ray induced DNA damage by cytosine arabinoside and hydroxyurea. Phamacol. Ther. 31: 166-176.

7. Fram, R. J. and Kufe, D. W. 1985. Effect of 1-beta-D arbinofuranosyl cytosine and hydroxyurea. Biochem. Phramacol. 34: 2557-2560.

8. Gottifredi, V., Shieh, S.-Y., Taya, Y. and Prives, C. 2001. p53 accumulates but is functionally impaired when DNA synthesis is blocked. Proc. Natl. Acad. Sci. U.S.A. 98: 1036-1041.

9. Greenwood, S. K., Armstrong, M. J., Hill, R. B., Bradt, C.I., Johnson, T. E., Hilliard, C. A. and Galloway, S. M. 1998. Fewer chromosome aberrations and earlier apoptosis induced by DNA synthesis inhibitors, a topoisomerase II inhibitor or alkylating agents in human cells with normal compared with mutant p53. Mutat. Res. 401: 39-53.

10. Gui, C. Y., Jiang, C., Xie, H. Y. and Qian, R. L. 1997. The apoptosis of HEL cells induced by hydroxyurea. Cell Res. 7: 9197.

11. Hayashi, M., Ishimori, K., Maeda, A., Watanabe, T., Arai, S. and Okui, T. 1996. Radioresistant DNA synthesis in fibroblast cell lines derived from LEC strain rats. Mutat. Res. 352: 117 121.

12. Hayashi, M., Okui, T., Endoh, D., Sato, F., Kasai, N. and Namioka, S. 1994. Radiation-hypersensitivity of LEC strain rats controlled by a single autosomal recessive gene. Mutat. Res. 314: 135-142.

13. Hayashi, M., Uhehara, K., Ichikawa, Y., Arai, S., Isogai, E. and Okui, T. 1998. Higher sensitivity in induction of apoptosis in fibroblast cell lines derived from LEC strain rats to UV-irradiation. J. Vet. Med. Sci. 60: 207-212.

14. Hayashi, M., Uehara, K., Kirisawa, R., Endoh, D., Arai, S. and Okui, T. 1997. Abnormal G1 arrest in the cell lines from LEC strain rats after X-irradiation. J. Vet. Med. Sci. 59: 769-773.

15. Hickman, J. A. 1992. Apoptosis induced by anticancer drugs. Cancer Metastasis Rev. 11: 121-139.

16. Kastan, M. B., Onyekwere, O., Sidransky, D., Vogelstein, B. and Craig, R. W. 1991. Participation of p53 protein in the cellular response to DNA damage. Cancer Res. 51: 6304-6311.

17. Kuo, M.-L., Kunugi, K. A., Lindstrom, M. J. and Kinsella, T. J. 1997. The interaction of hydroxyurea and ionizing radiation in human cervical carcinoma cells. Cancer J. Sci. Am. 3: 163173.

18. Lerner, H. J., Beckloff, G. L. and Goodwin, M. D. 1970. Treatment of astocytoma with hydroxyurea and ionizing radiation. Am. Surg. 36: 401-402.

19. Levin, V. A., Rodriquez, L. A. and Edwards, M. S. 1985. Treatment of medulloblastoma with procarbazine, hydroxyurea, and reduced radiation doses to whole brain and spine. $J$. Neurosurg. 68: 383-387.
20. Lindsay, H., Griffiths, D., Edwards, R., Christensen, P., Murray, J., Osman, F., Walworth, N. and Carr, A. 1998. S-phasespecific activation of Cds1 kinase defines a subpathway of the checkpoint response in Schizosaccharomyces pombe. Genes Dev. 12: 382-395.

21. Links, S. P., Clarkin, K. C., Leonardo, di A., Tsou, A. and Wahl, G. M. 1996. A reversible, p53-dependent G0/G1 cell cycle arrest induced by ribonucleotide depletion in the absence of detectable DNA damage. Genes Dev. 10: 934-947.

22. Matsuoka, S., Rotman, G., Ogawa, A., Shiloh, Y., Tamai, K. and Elledge, S. J. 2000. Ataxia telangiectasia-mutated phosphorylates Chk2 in vivo and in vitro. Proc. Natl. Acad. Sci. U.S.A. 97: 10389-10394.

23. Nelson, W. G. and Kastan, M. B. 1994. DNA strand breaks: the DNA template alterations that trigger p53-dependent DNA damage response pathways. Mol. Cell. Biol. 14: 1815-1823.

24. Okui, T., Endoh, D., Arai, S., Isogai, E. and Hayashi, M. 1996. Cross-sensitivity of X-ray-hypersensitive cells derived from LEC strain rats to DNA-damaging agents. J. Vet. Med. Sci. 58: 1067-1071.

25. Okui, T., Endoh, D. and Hayashi, M. 1999. Deficiency in fast repair process of potentially lethal damage induced by X-irradiation in fibroblasts derived from LEC strain rats. Mutat. Res. 435: $81-88$.

26. Piver, M. S., Barlow, J. J. and Vongtama, V. 1977. Hydroxyurea as a radiation sensitizer in women with carcinoma of the uterine cervix. Am. J. Obstet. Gynecol. 129: 379-383.

27. Radford, I. R. 1986. Evidence for a general relationship between the induced level of DNA double-strand breakage and cell-killing after $\mathrm{X}$-irradiation of mammalian cells. Int. J. Radiat. Biol. 49: 611-620.

28. Sasaki, M., Yoshida, M. C., Kagamori, K., Takeichi, N., Kobayashi, H., Dempo, K. and Mori, M. 1985. Spontaneous hepatitis in an inbred strain of Long-Evans rats. Rat News Lett. 14: 46.

29. Sinclair, W. K. 1968. The combined effect of hydroxyurea and X-rays on Chinese hamster cells in vitro. Cancer Res. 28: 198206.

30. Skoog, L. and Bjursell, G. 1972. Nuclear and cytoplasmic pools of deoxyribonucleoside triphosphates in Chinese hamster ovary cells. J. Biol. Chem. 249: 6434-6438.

31. Thelander, R. and Reichard, P. 1979. Reduction of ribonucleotides. Annu. Rev. Biochem. 48: 133-158.

32. Ward, J. F., Joner, E. I. and Blakely, W. F. 1984. Effects of inhibitors of DNA strand break repair on HeLa cell radiosensitivity. Cancer Res. 44: 59-63.

33. Yonish-Rouach, E., Grunwald, D., Wilder, S., Kimchi, A., May, E., Lawrence, J.-J., May, P. and Oren, P. 1993. p53mediated cell death: relationship to cell cycle control. Mol. Cell. Biol. 13: 1415-1423.

34. Yoshida, M. C., Masuda, R., Sasaki, M., Takeichi, N., Kobayashi, H., Dempo, K. and Mori, M. 1987. New mutation causing hereditary hepatitis in the laboratory rat. J. Hered. 78: $361-$ 365 . 